\title{
COMPARISON OF INSTITUTIONAL DYNAMICS OF REGIONAL DEVELOPMENT PUBLISHING AND PRINTING ACTIVITIES IN UKRAINE: METHODOLOGICAL AND PRACTICAL ASPECTS
}

\author{
Volodymyr BAZYLIUK ${ }^{1}$, Andriy SHTANGRET ${ }^{(\mathbb{D}}$, Oleksandr SYLKIN $^{3}{ }^{(1)}$, \\ Iryna BEZPALKO ${ }^{4}$
}

\begin{abstract}
Faculty of Media Communications and Entrepreneurship, Ukrainian Academy of Printing, Lviv, Ukraine E-mails: ${ }^{1} b v b . u a d @ u k r . n e t ;{ }^{2}$ shtangret.am@ukr.net; ${ }^{3}$ sylkin_os@ukr.net; ${ }^{4}$ irynabs83@i.ua (correspondingauthor)
\end{abstract}

Received 27 December 2018; accepted 18 February 2019

\begin{abstract}
The study of the impact of institutions on the economy necessitates the assessment of such impacts and the definition of a clear list of methods and criteria for evaluation. The purpose of our research is the formation of a methodological approach that would allow to compare the institutional dynamics of the regional development of publishing and printing activities. In the process of scientific research, the method of modified gravity modeling was used. The objective of the study is the publishing and printing activity and the assessment of its development. Information base of research on the main results of the publishing and printing activities in three regions - Kyiv (city), Kharkiv and Lviv regions. The study period is 4 years. Economic and mathematical calculations according to the method of comparing the institutional dynamics of the regional development of the PPA presented in this paper are based on the method of modified gravity modeling. Were obtained data on the institutional distance between the leading regions of publishing and printing activities, confirming the conclusions about the presence of significant disparities in the development of activities. The methodological approach to comparing the institutional dynamics of regional development activities (based on a modified gravity model) will allow to assess the impact of basic institutions on the regional development of PPA and the possibility of a quantitative comparison of such effects. The presented approach is based on the concept of institutional distance between points in the space of indices of institutional development of activities in the two regions under consideration.
\end{abstract}

Keywords: institutional environment, region, publishing, printing, publishing and printing activity, development and modified gravity model.

JEL Classification: E02, 011, L82, R10.

\section{Introduction}

\section{Problem statement}

Recently, issues related to the assessment of non-economic factors in the development of socio-economic systems have become widespread, due to the process of constantly searching for ways to increase the competitiveness not only of individual subjects of socio-economic relations, but territorial systems at both regional and national levels. In this regard, the search for solutions to the problem of creating an effective institutional environment, and, consequently, a competitive socio-economic system, acquires particular importance. One of the important directions of solving the task is the formation of effective methods for assessing and comparing the development of industries in the regions. Determining the degree of influence of institutional parameters on the development of complex socio-economic systems in the regions is not easy, because institutional influences are often measured not by quantitative, but by qualitative indicators. The complexity of solving the problem lies in the adequacy of interpretation and the combination of qualitative and quantitative parameters and the development of approaches to expression with the help of quantitative parameters of qualitative. Considering the task, a promising approach is the use of a modified gravity model for comparing the institutional

Copyright (C) 2019 The Authors. Published by VGTU Press.

This is an Open Access article distributed under the terms of the Creative Commons Attribution License (http://creativecommons.org/licenses/by/4.0/), which permits unrestricted use, distribution, and reproduction in any medium, provided the original author and source are credited.. 
dynamics of the regional development of publishing and printing activities (PPA).

\section{Aim of the research}

The aim of the research is the formation of the theoretical and methodological basis of the approach for comparing the institutional dynamics of the regional development of the PPA based on the modified gravity model.

\section{Information base of the research}

Information base of research on the main results of the publishing and printing activities in three regions - Kyiv (city), Kharkiv and Lviv regions. The study period is 4 years. Economic and mathematical calculations according to the method of comparing the institutional dynamics of the regional development of the PPA presented in this paper are based on the method of modified gravity modeling.

\section{Literature review}

For the first time in economics, often used by physicists since Newton, the gravity model was used to study the problems of the foreign trade of Tinbergen (1962) and quickly gained popularity and widespread use. Most of the economic works in which studies were conducted using a gravity model dealing with problems of foreign trade. It was created many modifications of the model. In particular, the Rose (2004) work in which the model is used to evaluate the World Trade Organization, should be noted. In addition, the proposed model is applied in other areas of economic research. So, Helpman and Krugman (1985) adapt the gravity model to study the market of monopolistic competition. Others, Redding and Venables (2004) modify the gravity model and adapt it for the development of the theory of new economic geography.

Domestic scientists study empirically mainly the influence of the institutional environment on the development of economic sectors based on the ratings of international organizations. The works of Goblik (2018), Zaplatinsky (2013), Sanina (2005), Yurkiv (2012) and others are devoted to this area. However, the question of assessing the impact of institutions on the industry through the prism of regional development is not sufficiently covered in the scientific literature.

At present, there is not enough theoretical groundwork for studying the influence of the institutional environment on the knowledge economy. There are works that explore the general issues of the development of the knowledge dissemination. So, Sagiyeva and others (2018) explores the intellectual contribution to the development of the knowledge dissemination in emerging markets. Another group of scientists headed by Mamedov et al. (2018) is studying the effect of artificial intelligence on the sustainable economic development of economies. However, there are practically no works that would investigate the influence of individual components on the development of the knowledge economy. An important component that forms its basic basis is the PPA. Activity plays an important role in the nationalcultural formation of the nation, its political culture, an appropriate level of education, and the exchange of achievements and experience. However, the transformation and adaptation of enterprises efficiency to the new conditions of institutional and economic conditions of management is slow, without the expected significant positive changes. Such trends determine the urgent need to find new approaches to assessing the impact of institutions on the PPA in order to accelerate its development.

Such studies are of particular relevance at the regional level, where there are significant disparities in the development of the PPA of Ukraine. There is a significant amount of work that explores the role of institutions in the development of regional economies. Thus, Hrabar (2012) analyzes the institutional features of the systemic development of regions, and Baldwin et al. (2001) examines the influence of institutional factors on economic growth and the agglomeration effect, which allows them to increase their effect and speed up the development of urban agglomerations and individual regions. However, the study of the impact of institutions on the development of PPA and the assessment of such actions in a regional context have not yet been carried out.

It can be said that the study of the characteristics of regional development is increasingly used to synthesize various kinds of theories based on an institutional platform. This allows us to analyze and determine the development prospects not only of the region as a whole, but also explore the specifics of the development of a particular regional system and its interaction with other regional subsystems. In our opinion, the approach of the study of regional economic systems from the standpoint of the influence of the totality of institutions is a quite promising. This approach can be effectively applied on the basis of the theoretical concept of the institution formed by Makarov (2002) as a fairly stable coalition of primary economic agents.

An interesting approach is proposed by Hamalainen (2003), considering the sectoral and regional features of production systems and can be adapted for institutional analysis of the PPA and building a system for assessing the influence of institutional factors on economic growth at the national and regional levels. However, in our opinion, using the indicator of institutional stability as a criterion for differentiation is difficult, because stability depends on a large number of contextual conditions and institutional links.

Despite the widespread use of the gravity model, in the framework of the study, we suggest using it not to analyze international trade and compare differences between different countries, but to make a comparative assessment of the influence of institutions on the development of PPA in different 
regions. From this position, an interesting approach of the using of the gravity model, is the work of Frankel (1997), who tried to describe regional features using it.

However, the methodologies of applying this approach for comparing the development of industries in the regions under the influence of institutional factors have not received further broad development, and causes scientific interest for our study.

\section{Research model}

The development of the gravity model known to physicists since Newton in economic thought was provided by Tinbergen (1962). A feature of this approach, given the subject of our research was that unlike the already-existing approaches to analysis (first of all, they were based on interstate differences in GDP levels), the model additionally considered a number of significant factors of institutional dynamics. This approach quickly gained popularity and was used by researchers for a diverse analysis of economic processes. The functional form of the modified gravity model as a whole has the following formula (1):

$$
F_{i j}=\frac{G \times\left(M_{i} \times M_{j}\right)}{\text { Dinst }_{i j}},
$$

where $F_{i j}$ - Trading flows, for example, the sum of exports and imports of countries " $i$ " and " $j$ "; $M_{i}, j$ - economic masses, for example, GDP of countries or regions " $i$ " and “j”, respectively; Dist $_{i j}$ - geographical distances between countries " $i$ " and " $j$ "; $G$ is the gravity constant.

Most of the works in which this approach was used were related to studies that described the volume of trade between countries using a gravity model.

In our study, we propose to use the gravity model not to analyze trade turnover between countries, but to analyze differences in the institutional dynamics of the development of PPA in the regions of Ukraine. The development of the PPA in the regions, according to our hypothesis, occurs under the significant influence of the institutional environment and innovative institutions of the leading regions of activity. The evolution of institutions is directly related to their partial borrowing (import of institutions) from leading regions to regions where PPA does not occupy leading positions. All that facilitates the interaction of regions will contribute to the convergence of their institutions. Moreover, one should expect that the institutions of economically developed regions that are leaders of the FAP, as the level of cooperation grows, will be more likely to be borrowed by less developed regions of activity. The choice of a gravity model for this study is explained by the fact that the development of cooperation between the regions will contribute to the convergence of their institutions.

Let us proceed to the direct formation of a methodological approach. We believe that the functioning and cooperation of the PPA in different regions of Ukraine is influenced by various institutional factors: historical and geographical; distances between regions; the presence of the state border; culture; availability of printing materials; research institutions; personnel training.

To determine differences in the influence of basic institutions, we suggest applying the concept of institutional distance between two regions. By institutional distance $i$ and “ $j$ ” ( Dinst $_{i j}$ ), we understand the distance between points in the space of indices of institutional development of publishing and printing activities in two compared regions. In general, the calculation of institutional distance will take the formula (2):

$$
\text { Dinst }_{i j}=\sqrt{\sum_{n=1}^{n}\left(\text { Iinst }_{i / n}-\text { Iinst }_{j / n}\right)^{2}},
$$

where Dinst $_{i j}$ is the institutional distance between regions " $i$ " and " $j$ "; $I_{\text {inst }}$ - the value of " $n$ " index assessment of the institutional impact on the development of publishing and printing activities; " $n$ " is the number of indices of institutional impact assessment; $i, j$ - comparative regions.

For the practical interpretation of our study, we propose, in order to estimate the institutional distances between the development of publishing and printing activities in the regions, to apply an approach based on the use of groups of indices.

Indices that take into account regional differences in the impact of institutions on the development of publishing and printing activities should, in our opinion, take into account the following features (Bazyliuk 2007):

- differences in the level of economic development of publishing and printing activities in the regions;

- geographical distances between regions;

- cultural and scientific characteristics;

- belonging to certain groups of economic development;

- material and technical component.

From the point of view of the goals of our analysis (assessment of the impact of economic institutions on publishing and printing activities), most of the above features can be assessed using a 6-component index, which is designed to reflect mainly the quality of economic institutions, whose functioning is largely related to the development of science and geographical factors. Given the above conditions, Formula (3) will take the following form:

$$
\begin{aligned}
& \text { Dinst }_{i j}=\log \left(\frac{Q_{i} / \text { Nb.e }_{\cdot i}}{Q_{j} / \text { Nb.e. } \cdot j_{j}}-1\right)+\log \left(\frac{\text { Dist }_{\cdot i j}}{W r_{\cdot{ }_{i}}+W r_{\cdot j}}\right)+ \\
& \operatorname{Com}\left(\operatorname{bord}_{i j}\right)+\operatorname{Com}\left(\text { science }_{i j}\right)+\log \left(\frac{\gamma N p r_{i}}{\gamma N p r_{j}}-1\right)+ \\
& \log \left(\frac{{\text { Co. } r_{\cdot} / Q_{i}}_{\text {Co.r. }_{\cdot j} / Q_{j}}}{1}\right)+G r . d_{\cdot i j} \text {, }
\end{aligned}
$$


where $\log \left(\frac{Q_{i} / N b \cdot e_{\cdot i}}{Q_{j} / N b \cdot e_{\cdot j}}-1\right)$ - the ratio of sales volume of products of enterprises PPA efficiency in the region $(Q)$ with the number of subjects of the industry in the region (Nb.e.). In order to ensure correct comparison of data in the numerator, it is necessary to submit a region with a large value of product sales per one enterprise for the considered pairs " $i$ " and " $j$ "; $\log \left(\frac{D_{i s t} \cdot i j}{W r_{\cdot i}+W r_{\cdot j}}\right)$ - geographical distance between regions " $i$ " and " $j$ ”. It is proposed to use a variable, calculated as the distance between regional centers $\left(\right.$ Dist $_{. i j}$ ) divided by the sum of the number of employees of publishing and printing activities $(W r$. ) In regions " $i$ ” and “ $j$. For information on the geographical distances between regional centers, we suggest using the Google Maps service; $\operatorname{Com}\left(\operatorname{bord}_{i j}\right)$ - dummy variables that takes the value 0 , if the regions have common features, and otherwise the variable is 1 ; Com $\left(\right.$ science $\left._{i j}\right)$ - dummy variablesthat assumes the value of 0 if there are institutions of higher education in both regions that train specialists for printing and / or research organizations researching the problems of PPA and 1 otherwise; $\log \left(\frac{\gamma N p r_{i}}{\gamma N p r_{j}}-1\right)$ - the ratio of the values of private enterprises of private property in the total set of subjects of publishing and printing activities between regions " $i$ " and " $j$ "; $\log \left(\frac{\text { Co. } r_{.} / Q_{i}}{\text { Co.r. } . j_{j} / Q_{j}}-1\right)$ - the ratio of the volume of operating expenses of the PPA in the region (Co.r.) with the number of industry entities in the region (Q.); Gr.d.ij - dummy variable for two groups of regions of the country by the level of economic development (in accordance with the classification proposed by the Ministry of Regional Development, Construction and Housing and Communal Services of Ukraine 2018). Dummy variable takes the value 0 , if both regions " $i$ " and " $j$ " are in the TOP-10 of the proposed classification, and 1 otherwise.

\section{Empirical results}

\subsection{Data and model specification}

The economic crisis that has been characteristic of Ukraine's industry in recent years, as well as its individual industries and complexes, is explained by the fact that during this period the institutions and economic mechanisms necessary for the successful functioning of a market economy are not fully developed and, as a result, work inefficiently. The list of the main institutional problems of the industry include: a sharp reduction in investment activity due to increased uncertainty and active hostilities in the east of the country, insecurity and uncertainty of property rights after privatization, inflation, a non-payment crisis, weak financial institutions, especially the securities market and long-term lending, crisis in the banking sector, the rapid devaluation of the national currency, imperfect law enforcement and judicial system and a many other important institutional factors. Under such conditions, the disorganization of the economic activity of enterprises and, as a result, a decline in production is inevitable. Under such economic conditions, there was a terminable need for urgent and immediate reforms, which are intended to move from an industrial to a post-industrial economy. The further fate of the entire Ukrainian economy and the existence of the state in its current form as a whole will depend on the quality and speed of the transformations.

Under the conditions of inevitable transformational processes, those industries, complexes and regions that are able to generate knowledge, correctly collect and process information, instantly respond to technological, social and economic institutional changes and, as a result, can "survive" and ensure their development.

These problems are also characteristic of publishing and printing activity. They are greatly enhanced and have a more significant impact on enterprises of activity due to specific features. As noted in their work Shvaika and Shtangret (2008), the value of efficiency, as a structural component of the economy, is determined not only by the size of its contribution to the country's GDP, is about $2 \%$, but primarily by its character, purpose, and place in society. Publishing and printing activities ensure the information development of society and the formation of public opinion through the production and distribution of printed information. Information product contributes to the formation and development of national consciousness, educational and cultural level, activating the solution of problems of social and economic importance, social progress, development of a legal society and a socially responsible state.

The formation of a new institutional structure of industry for the restructuring of the economy is a rather long and complicated process. In addition, differences in baseline conditions and dependence on previous development trajectories require close attention to the unique features of the institutional development of each component of the economy and PPA in particular. Social, cultural, political institutions are no less important for the modernization of activities than economic ones.

The analysis of modern processes of institutional changes in the PPA can not be multidisciplinary and should consider previous stages of development. According to this study, the directions and stages of the transformation of PPA in the conditions of a post-industrial society should be carried out considering the peculiarities of the formation of social capital, the evolution of technology, mentality, consumer culture and the political component. 
The functioning and cooperation of the PPA in different regions of Ukraine are influenced by various institutional factors: historical and geographical; distances between regions; the presence of the state border; culture; availability of printing materials; research institutions; personnel training.

Let us try to justify such differences from the standpoint of institutional theory. It is obvious that the institution of the state significantly influences the development of Kyiv as the capital of Ukraine. Here a significant number of printed products are produced in accordance with the state order: the available specialized enterprises for the production of securities; documentation of strict accountability. There are editorial offices of national newspapers and magazines of book outputs. In addition, the presence of a large number of central offices and productions of large companies leads to significant needs for blanks, packaging and labeling products. The institute of infrastructure has significant potential in the region: training; trade networks; financial and insurance companies; manufacturers and suppliers of printing materials; one of several manufacturers of printing equipment in Ukraine and a research institute. As says Shvaika (2005) a similar situation is characteristic of the Kharkiv region, where during the Kharkiv was the capital of Soviet Ukraine was concentrated and there remained a great potential, both of the PPA and other industries, education, scientific and technical activities, etc.

In the Lviv region, the potential is smaller compared to the previous two regions. However, in comparison with other regions, the region has a significant number of PPA subjects, with sufficient scientific potential in the form of a research institute and a higher educational institution the Ukrainian Academy of Printing. In the region there are manufacturers of materials and equipment for the needs of the activity, and its adhering close to the state line allows us to concentrate representative offices of foreign manufacturers of publishing and printing materials and equipment and to establish joint trade and production activities.

Therefore, it can be argued that such institutions as states and infrastructures have a significant impact on the development of PPA in some regions, while in others their action is not significant. For example, printing of books in accordance with the state order is carried out mainly in three of the above-mentioned regions, and only then it is distributed in other areas. Similar in content, there is a situation of the production the materials and equipment for the needs of the PPA.

These data give grounds to assert that, on the one hand, the influence of institutes for the dynamic development of activities in some regions contributes to the strengthening of cooperation between the latter and PPA in other regions where such influence is not significant. On the other hand, the strengthening of such interaction allows intensifying the process of institutional convergence: in order to facilitate mutual cooperation between the PPA of the regions, the latter are forced to adapt their institutions to each other. Under such conditions, the institutions of more economically developed regions of enhanced cooperation will be more likely to be borrowed from less developed regions.

The rationale for the use of the gravity model in our study is due to the fact that the intensification of cooperation between the subjects of the PPA in the regions, according to our hypothesis, leads to a decrease in regional imbalances in its development. So, factors that are capable of exploring the main differences regarding the functioning and development of PPA in the regions will allow assessing regional differences in the influence of basic institutions on the development of publishing and printing activities.

\subsection{Results and discussion}

We will offer a practical application of the above listed approach and will calculate the value of the institutional distance between the three regions leading in efficiency Kyiv (city), Kharkiv and Lviv regions. To do this, in Table 1 we give the initial calculation indicators based on official statistical data.

As a result of further processing of the initial data, we present the obtained results in Table 2 in accordance with the presented methodology.

The results obtained during the comparison the institutional distance between the three leading regions of the PPA, confirm our preliminary conclusions about the presence of significant disparities in the development of activity area. The institutional distance between the two leaders in the development of efficiency - the city of Kyiv and the Kharkiv region is insignificant, on average for the four years under consideration it was 1.79 points, compared to the region, it ranks third in terms of regional development - the Lviv region, the indicator under consideration tends to significant growth. Thus, the institutional distance between the leader of regional development in Kyiv and the Lviv region averages 3.55 points, and between Kharkiv and Lviv regions -4.98 points. Obviously, during the comparison other areas in which PPA does not occupy a leading position, with the leaders, the analyzed indicator will tend to further increase due to low performance indicators in these regions and the lack of infrastructure of the PPA.

\section{Conclusions}

This methodological approach to comparing the institutional dynamics of regional development activities (based on a modified gravity model) will allow to assess the impact of basic institutions on the regional development of PPA and the possibility of a quantitative comparison of such effects. The presented approach is based on the concept of institutional distance between points in the space of indices 
Table 1. Output indicators for calculation institutional distance between regions (source: authors 2018)

\begin{tabular}{|c|c|c|c|c|c|c|}
\hline \multirow[b]{2}{*}{ Region } & \multirow[b]{2}{*}{ Period } & \multicolumn{5}{|c|}{ Indicators of PPA } \\
\hline & & $\begin{array}{c}\text { Total number of } \\
\text { enterprises }\end{array}$ & $\begin{array}{c}\text { Number of } \\
\text { employees, per. }\end{array}$ & $\begin{array}{c}\text { Share of private } \\
\text { property } \\
\text { enterprises, } \%\end{array}$ & $\begin{array}{c}\text { Operating } \\
\text { expenses, } \\
\text { million UAH }\end{array}$ & $\begin{array}{l}\text { Net income from } \\
\text { sales of products } \\
\text { million UAH }\end{array}$ \\
\hline \multirow{4}{*}{ Kyiv (city) } & 2013 & 2072 & 16705 & 94.1 & 8916.5 & 8661.4 \\
\hline & 2014 & 2370 & 19741 & 94.2 & 8145.8 & 8058.2 \\
\hline & 2015 & 2984 & 22212 & 93.7 & 11268 & 8352.7 \\
\hline & 2016 & 2188 & 17926 & 93.4 & 10124 & 8451.7 \\
\hline \multirow{4}{*}{ Kharkiv region } & 2013 & 446 & 5628 & 90.2 & 1699.2 & 1778.3 \\
\hline & 2014 & 448 & 5732 & 90.5 & 1910.2 & 1850.2 \\
\hline & 2015 & 433 & 5393 & 91.0 & 2208.9 & 2106.5 \\
\hline & 2016 & 416 & 4776 & 91.1 & 2788.3 & 2839.5 \\
\hline \multirow{4}{*}{ Lviv region } & 2013 & 325 & 4080 & 87.6 & 487.9 & 525.2 \\
\hline & 2014 & 359 & 3731 & 87.8 & 555.6 & 577.0 \\
\hline & 2015 & 339 & 3289 & 87.6 & 503.3 & 493.2 \\
\hline & 2016 & 322 & 2760 & 87.3 & 717.9 & 738.7 \\
\hline
\end{tabular}

Table 2. Assessment of the index of the institutional development of institutional and polygraphic activities in the regions (source: authors 2018)

\begin{tabular}{|c|c|c|c|c|c|c|c|c|c|c|}
\hline \multirow[b]{2}{*}{ Regions } & \multirow[b]{2}{*}{ Period } & \multicolumn{7}{|c|}{ Comparative index } & \multirow[b]{2}{*}{ Dinst $_{i j}$} & \multirow[b]{2}{*}{$\begin{array}{l}\text { The average } \\
\text { value for the } \\
\text { analyzed pe- } \\
\text { riod Dinstij }\end{array}$} \\
\hline & & $\underbrace{\underset{0}{-1}}_{\substack{0 \\
0}}$ & 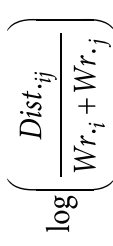 & $\frac{\overbrace{}^{5}}{\frac{5}{0}}$ & 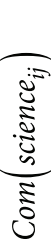 & $\underbrace{\sum_{\substack{\vdots \\
\vdots}}^{\vdots}}_{\substack{\infty \\
0}}$ & 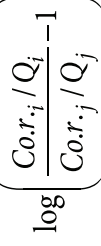 & t) & & \\
\hline \multirow{4}{*}{$\begin{array}{l}\text { Kyiv } \\
\text { (city) and } \\
\text { Kharkiv } \\
\text { region }\end{array}$} & 2013 & 0.05 & 0.02 & 1 & 0 & 0.04 & 0.13 & 0 & 1.24 & \multirow{4}{*}{1.79} \\
\hline & 2014 & 0.21 & 0.02 & 1 & 0 & 0,04 & 0.24 & 0 & 1.51 & \\
\hline & 2015 & 0.74 & 0.02 & 1 & 0 & 0.03 & 0.35 & 0 & 2.14 & \\
\hline & 2016 & 0.77 & 0.02 & 1 & 0 & 0.03 & 0.45 & 0 & 2.27 & \\
\hline \multirow{4}{*}{$\begin{array}{l}\text { Kyiv } \\
\text { (city) } \\
\text { and Lviv } \\
\text { region }\end{array}$} & 2013 & 1.49 & 0.03 & 1 & 0 & 0.07 & 1.75 & 0 & 4.34 & \multirow{4}{*}{3.55} \\
\hline & 2014 & 1.11 & 0.02 & 1 & 0 & 0.07 & 1.22 & 0 & 3.42 & \\
\hline & 2015 & 0.93 & 0.02 & 1 & 0 & 0.07 & 1.55 & 0 & 3.57 & \\
\hline & 2016 & 0.68 & 0.03 & 1 & 0 & 0.07 & 1.08 & 0 & 2.86 & \\
\hline \multirow{4}{*}{$\begin{array}{l}\text { Kharkiv } \\
\text { and Lviv } \\
\text { region }\end{array}$} & 2013 & 1.37 & 0.105 & 1 & 0 & 0.03 & 1.44 & 0 & 3.95 & \multirow{4}{*}{4.98} \\
\hline & 2014 & 1.56 & 0.107 & 1 & 0 & 0.031 & 1.75 & 0 & 4.45 & \\
\hline & 2015 & 2.35 & 0.117 & 1 & 0 & 0.039 & 2.44 & 0 & 5.95 & \\
\hline & 2016 & 1.98 & 0.135 & 1 & 0 & 0.043 & 2.02 & 0 & 5.56 & \\
\hline
\end{tabular}


of institutional development of activities in the two regions under consideration. Practical application of this approach allows to substantiate the differences in the influence of institutions on the development of PPA in the regions and to obtain the following results:

1. The greater the differences in the economic development of activities in these territories, the greater the institutional distance between the level of development of the PPA in the two compared regions.

2. General historical, scientific, and research development, which is assessed through the availability of scientific and research institutions to study the problems of PPA, to a greater extent than geographical proximity, reduces the magnitude of the gap in institutional impacts.

3. By analyzing institutional distances, it is possible to identify the prerequisites for clustering PPA between regions, on the one hand, according to the economic principle (available economic results and potential), on the other - on a geographical basis (combining geographically territories).

4. Institutional differences are largely related to historical heritage and geographical environment, so such differences are quite stable and inertial.

\section{Author contributions}

The authors contributed equally.

\section{Disclosure statement}

The authors do not have any conflict of interest.

\section{References}

Bazyliuk V (2007) Publishing and printing activity in the regions of Ukraine: theoretical and institutional and economic foundations of development. Ukrainian Academy of Printing, Lviv.

Baldwin R, Martin P, Ottaviano G (2001) Global income divergence, trade and industrialization: The geography of growth takeoff. Journal of Economic Growth (6): 5-37. https://doi. org/10.1023/A:1009876310544

Hamalainen T (2003) National competitiveness and economic growth: the changing determinants of economic performance in the world economy. Cheltenham, Edward Elgar. https://doi. org/10.4337/9781781950302

Helpman E, Krugman P (1985) Market structure and foreign trade. Cambridge: MIT Press.

Hrabar MV (2012) Institutional foundations of systematic development of the region. Economic Space 67: 93-103.
Goblik V (2018) Assessment of the impact of the institutional environment on the development of foreign economic relations in cross-border regions. Economy and Society. Science article. World economy and international economic relations 15: 24-27.

Makarov V (2002) On mathematical models of competition between enterprises. Economic science of modern Russia 1: 5-9.

Frankel J (1997) Regional trading blocs in the world economic system. Institute for International Economics, Washington DC.

Mamedov O, Tumanyan Y, Ishchenko-Padukova O, Movchan I (2018) Sustainable economic development and post-economy of artificial intelligence. Entrepreneurship and Sustainability Issues 6 (2): 1028-1040. https://doi.org/10.9770/ jesi.2018.6.2(37)

Monitoring of the socio-economic development of regions for 2017. Ministry of Regional Development, Construction, Housing and Communal Services of Ukraine. Regional Development Department in May 2018 (rating).

Redding S, Venables A (2004) Economic geography and international inequality. Journal of International Economics 62: 53-82. https://doi.org/10.1016/j.jinteco.2003.07.001

Rose A (2004) Do we really know that the WTO increases trade? American Economic Review 94 (1): 98-114. https://doi. org/10.1257/000282804322970724

Sagiyeva R, Zhuparova A, Ruzanov R, Doszhan R, Askerov A (2018) Intellectual input of development by knowledge-based economy: problems of measuring in countries with developing markets. Entrepreneurship and Sustainability Issues 6 (2): 711-728. https://doi.org/10.9770/jesi.2018.6.2(17)

Sanina O (2005) Features of institutional analysis of the private sector of Ukraine's economy. Scientific Bulletin of the Lviv Law Institute of the Ministry of Internal Affairs of Ukraine 1: 239-247.

Shvaika L, Shtangret A (2008) Economics of the publishing and printing industry. Ukrainian Academy of Printing, Lviv.

Shvaika L (2005) Development and regulation of publishing business. Ukrainian Academy of Printing, Lviv.

Tinbergen J (1962) Shaping the world economy: Suggestions for an international economic policy. New York, The Twentieth Century Fund.

Yurkiv N (2012) Economic and institutional prerequisites for economic security in the real sector of the economy. Project Management and Production Development: Collection of Scientific Works 1 (41): 44-50. Lugansk: V. Dahl East Ukrainian National University Press.

Zaplatinsky M (2013) Institutional and economic factors of development enterprise. Scientific bulletin of the Lviv University. Series Economics 49: 311-317. 